Article

\title{
Patterns of Drought Response of 38 WRKY Transcription Factors of Zanthoxylum bungeanum Maxim.
}

\author{
Xitong Fei, Lixiu Hou, Jingwei Shi, Tuxi Yang, Yulin Liu * and Anzhi Wei * \\ College of Forestry, Northwest Agriculture and Forestry University, Yangling 712100, China; \\ feixt666@163.com (X.F.); houlixiu1994@163.com (L.H.); shijingweijw@163.com (J.S.); y2848@126.com (T.Y.) \\ * Correspondence: lyl12504001@126.com (Y.L.); Weianzhi@126.com (A.W.); Tel.: +86-029-8708-2211 (A.W.)
}

Received: 21 November 2018; Accepted: 21 December 2018; Published: 24 December 2018

\begin{abstract}
The WRKY family of transcription factors (TFs) includes a number of transcription-specific groupings that play important roles in plant growth and development and in plant responses to various stresses. To screen for WRKY transcription factors associated with drought stress in Zanthoxylum bungeanum, a total of $38 \mathrm{ZbWRKY}$ were identified and these were then classified and identified with Arabidopsis WRKY. Using bioinformatics analyses based on the structural characteristics of the conservative domain, 38 WRKY transcription factors were identified and categorized into three groups: Groups I, II, and III. Of these, Group II can be divided into four subgroups: subgroups IIb, IIc, IId, and IIe. No ZbWRKY members of subgroup IIa were found in the sequencing data. In addition, $38 \mathrm{ZbWRKY}$ were identified by real-time PCR to determine the behavior of this family of genes under drought stress. Twelve ZbWRKY transcription factors were found to be significantly upregulated under drought stress and these were identified by relative quantification. As predicted by the STRING website, the results show that the WRKYs are involved in four signaling pathways—-the jasmonic acid (JA), the salicylic acid (SA), the mitogen-activated protein kinase (MAPK), and the ethylene signaling pathways. ZbWRKY33 is the most intense transcription factor in response to drought stress. We predict that WRKY33 binds directly to the ethylene synthesis precursor gene $A C S 6$, to promote ethylene synthesis. Ethylene then binds to the ethylene activator release signal to activate a series of downstream genes for cold stress and osmotic responses. The roles of ZbWRKY transcription factors in drought stress rely on a regulatory network center on the JA signaling pathway.
\end{abstract}

Keywords: Zanthoxylum bungeanum maxim.; transcription factor; WRKY; bioinformatics; abiotic stress

\section{Introduction}

Transcription factors (TFs) are a class of proteins that specifically bind to cis-acting elements in the promoter region of eukaryotic genes. Through interaction between these and other proteins, the activation of the gene or the inhibition of transcription is achieved, thereby ensuring that the target gene is expressed at a specific intensity and at a specific time and place [1,2]. A wide variety of transcription factors are involved in the life processes of plants. They can be divided into many different types or families depending on the differences in sequence characteristics and functions. Families include WRKY, AP2/ERF, and MYB. Among these, WRKY is one of the largest in plants [3]. In 1994, the WRKY transcription factor SPF1 was discovered in sweet potato [4] and then cloned in Arabidopsis thaliana [5], rice [6], tomato [7], and cucumber [8].

The WRKY transcription factor has one or two WRKY domains containing the signature WRKYGQK peptide, which consists of approximately 60 highly conserved amino acid residues that 
bind to the W-box in the DNA sequence at the C-terminus of the WRKY domain. It also has a zinc finger structure (CX4-5CX22-23HX1H or CX7CX23HX1C), which is key in determining whether the WRKY protein binds to the related gene cis-acting element Wbox (TTGACT/C) [9,10]. According to the number of WRKY domains and the characteristics of zinc finger structures, WRKY proteins can be divided into three main types. Group I has two WRKY domains and the zinc finger structure type is $\mathrm{C} 2 \mathrm{H} 2$. Groups II and III contain only one WRKY domain. In these, the zinc finger structure type of the group III members is $\mathrm{C} 2 \mathrm{HC}$, and of the group II members is $\mathrm{C} 2 \mathrm{H} 2$. According to evolutionary relationships and certain amino acid motifs in the WRKY domain, group II WRKY transcription factors can be subdivided into five subgroups: subgroups IIa to IIe.

A large number of WRKY gene families play important roles in plant physiological processes such as growth and metabolism [11], response to various stresses [12,13], and defense responses to pathogens [14]. The WRKY family plays many key roles-especially in drought defense. $M t W R K Y 76$ responds rapidly under drought stress, its overexpression increasing drought tolerance in Medicago truncatula [15]. VIWRKY48 was confirmed to increase catalase, peroxidase, and superoxide dismutase antioxidant enzymes under drought stress. This not only increases drought resistance in grapes but also plays an important role in resisting powdery mildew infection [16]. In Arabidopsis, WRKY46 has been shown to regulate responses to drought stress and is also involved in regulating light-dependent stomatal opening [17].

Zanthoxylum bungeanum (ZB), also known as Chinese prickly ash, belongs to the family Rutaceae and has a long history of cultivation in China. It is used both as a traditional medicine and as a food. Its fruit skin is one of the eight condiments [18], because of its unique numbing (anaesthetic) peppery taste. It has become an irreplaceable ingredient in traditional foods such as hot pot. In addition, $Z B$ has a well-developed root system and excellent soil-fixing ability. Hence, it is also an ecological tree species for greening barren hills and conserving both water and soil. It plays an important role in the project of returning farmland to forest.

Zanthoxylum bungeanum is a drought-tolerant tree but, as an economic species, the development of the associated Chinese prickly ash industry can be seriously affected by geographical conditions and by variations in weather. Drought causes poor growth of the pepper and excessive fall of both flowers and fruits, and this has serious consequences for both yield and yield stability [19]. Therefore, increasing drought resistance and thus stabilizing the yield of Zanthoxylum bungeanum through genetic breeding will be important for ensuring the development of the Chinese prickly ash industry. Moreover, there are few studies on the transcription factors of $Z B$ that seek to discover the corresponding $Z b W R K Y$ transcription factor under drought stress. These may provide valuable reference points for breeding drought-stress resistance into $Z B$.

\section{Results}

\subsection{Identification of the WRKY Proteins in Zanthoxylum bungeanum}

From the transcriptome of the ZB skin, 50 WRKY candidate genes were initially screened, based on the annotation information. The conserved domain of the WRKY gene was determined by the conservative domain prediction software Pfam to verify the correctness of the sequence alignment search. In the end, 38 sequences were identified as WRKY conserved domains. The sequence of ZbWRKY proteins was named according to the BLAST results of the Zanthoxylum protein sequence and the WRKY protein sequences of Arabidopsis thaliana (Table 1). 
Table 1. Zanthoxylum bungeanum WRKY protein sequence classification and domain.

\begin{tabular}{|c|c|c|c|c|}
\hline Number & Name & Group & Structural Domain & $\begin{array}{l}\text { Homologous Gene of } \\
\text { Arabidopsis thaliana }\end{array}$ \\
\hline 1 & ZbWRKY43 & I & WRKYGQK + WRKYGQK + C2H2 & KDO64417.1 \\
\hline 2 & ZbWRKY13 & $\mathrm{I}$ & WRKYGQK + WRKYGQK + C2H2 & XP_006464513.1 \\
\hline 3 & ZbWRKY47 & II-b & WRKYGQK + C2H2 & XP_006492428.1 \\
\hline 4 & ZbWRKY75 & $\mathrm{I}$ & WRKYGQK + WRKYGQK + C2H2 & XP_006436871.1 \\
\hline 5 & ZbWRKY41 & III & WRKYGQK + C2HC & XP_011022522.1 \\
\hline 6 & ZbWRKY74 & II-d & WRKYGQK + C2H2 & KDO54401.1 \\
\hline 7 & ZbWRKY24 & I & WRKYGQK + WRKYGQK + C2H2 & XP_006431962.1 \\
\hline 8 & ZbWRKY24(2) & $\mathrm{I}$ & WRKYGQK + WRKYGQK + C2H2 & XP_006431962.1 \\
\hline 9 & ZbWRKY22 & II-e & WRKYGQK + C2H2 & XP_006444950.1 \\
\hline 10 & ZbWRKY70 & III & WRKYGKK mutation & XP_006435943.1 \\
\hline 11 & ZbWRKY49 & II-c & WRKYGQK + C2H2 & XP_006480891.1 \\
\hline 12 & ZbWRKY50 & II-c & WRKYGQK + C2H2 & XP_006474455.1 \\
\hline 13 & ZbWRKY50(2) & II-c & WRKYGQK + C2H2 & XP_006474454.1 \\
\hline 14 & ZbWRKY71 & I & WRKYGQK + WRKYGQK + C2H2 & KDO78100.1 \\
\hline 15 & ZbWRKY70(2) & III & WRKYQGQK + C2HC & XP_006481203.1 \\
\hline 16 & ZbWRKY65 & II-e & WRKYGQK + C2H2 & XP_006467614.1 \\
\hline 17 & ZbWRKY7 & II-d & WRKYGQK + C2H2 & KDO84087.1 \\
\hline 18 & ZbWRKY31 & I & WRKYGQK + WRKYGQK + C2H2 & KDO54715.1 \\
\hline 19 & ZbWRKY15 & II-d & WRKYGQK + C2H2 & XP_006425967.1 \\
\hline 20 & $Z b W R K Y 7(2)$ & II-d & WRKYGQK + C2H2 & XP_006494483.1 \\
\hline 21 & ZbWRKY17 & II-d & WRKYGQK + C2H2 & XP_006483548.1 \\
\hline 22 & ZbWRKY33 & $\mathrm{I}$ & WRKYGQK + WRKYGQK + C2H2 & XP_012089749.1 \\
\hline 23 & ZbWRKY4 & I & WRKYGQK + WRKYGQK + C2H2 & XP_006482724.1 \\
\hline 24 & ZbWRKY53 & III & WRKYQGQK + C2HC & XP_006491244.1 \\
\hline 25 & ZbWRKY75(2) & $\mathrm{I}$ & WRKYGQK + WRKYGQK + C2H2 & AEO31515.1 \\
\hline 26 & ZbWRKY70(3) & III & WRKYQGQK + C2HC & KDO67551.1 \\
\hline 27 & ZbWRKY14 & II-e & WRKYGQK + C2H2 & XP_006448817.1 \\
\hline 28 & ZbWRKY20 & II-c & WRKYGQK + C2H2 & XP_006452514.1 \\
\hline 29 & ZbWRKY47(2) & II-b & WRKYGQK + C2H2 & XP_006444621.1 \\
\hline 30 & ZbWRKY32 & I & WRKYGQK + WRKYGQK + C2H2 & XP_006453624.1 \\
\hline 31 & ZbWRKY44 & I & WRKYGQK + WRKYGQK + C2H2 & XP_006428919.1 \\
\hline 32 & ZbWRKY53(2) & III & WRKYQGQK + C2HC & XP_006439376.1 \\
\hline 33 & ZbWRKY2 & I & WRKYGQK + WRKYGQK + C2H2 & XP_006474751.1 \\
\hline 34 & ZbWRKY4(2) & I & WRKYGQK + WRKYGQK + C2H2 & KDO83046.1 \\
\hline 35 & ZbWRKY1 & I & WRKYGQK + WRKYGQK + C2H2 & XP_006447745.1 \\
\hline 36 & ZbWRKY41(2) & III & WRKYQGQK + C2HC & XP_006490540.1 \\
\hline 37 & ZbWRKY51 & II-c & WRKYGQK + C2H2 & XP_006464492.1 \\
\hline 38 & ZbWRKY14(2) & II-e & WRKYGQK + C2H2 & KDO76342.1 \\
\hline
\end{tabular}

\subsection{ZbWRKY Gene Phylogenetic Tree Analysis and Group Identification}

The WRKY domain sequence of ZbWRKY protein was clustered using MEGA 7.0 software by analyzing the conserved domain characteristics of the WRKY proteins of Arabidopsis thaliana. The grouping of ZbWRKY proteins was determined using the type of known Arabidopsis and the citrus (Citrus sinensis) WRKY protein. The evolution of the ZbWRKY protein sequence was analyzed by MEGA 7.0. The ZbWRKY gene family was divided into Groups I, II, and III. Group II was further 
divided into four subgroups: subgroups II-b, II-c, II-d, and II-e (Figure 1 and Table 1). ZbWRKY41, ZbWRKY53, and ZbWRKY70 are difficult to cluster with other sequences, probably because of the large numbers of mutations in these sequences. From the protein sequence analysis, the ZbWRKY70 gene was mutated from the WRKYGQK to the WRKYGKK in the WRKY domain. ZbWRKY41 and ZbWRKY53 have a large number of mutation points outside the WRKY conserved region (Figure 2).

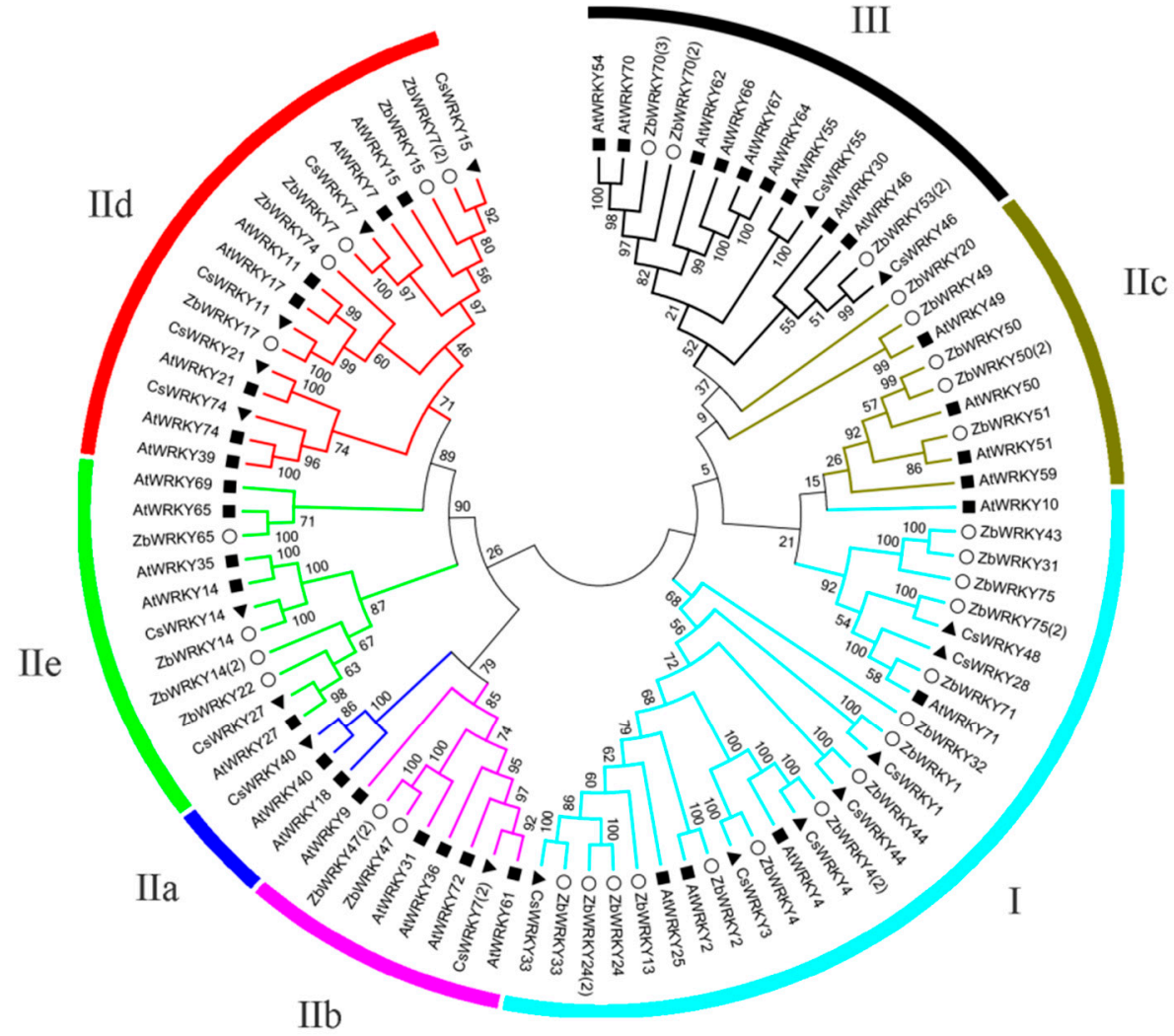

Z ZbWRKYs

A CsWRKYs

$\mathrm{IIb}$

Figure 1. Phylogenetic tree of the WRKY protein. 
ZbWRKY43

ZbWRKY13

ZbWRKY75

ZbWRKY24

ZbWRKY24_2

ZbWRKY71

ZbWRKY31

ZbWRKY33

ZbWRKY4

ZbWRKY75 2

ZbWRKY32

ZbWRKY44

ZbWRKY2

ZbWRKY4_2

ZbWRKY1

Consensus

DGYRWRKYGQKVVKNSEFPRSYYKCTH . . KGCHV̄KKQVQRSCKDEQIVVTTYLGMHTH DGYKWRKYGQKVVKNTQHPRSYYRCTQ . . . ENCRVKKRVERLAELERMVITTYEGRHVH DGYRWRKYGQKIVKNSNFPRSYYKCTH . . . KGCNVKKQVQRNSKDEQIVVTTYEGIHTH

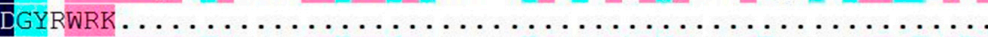

DVWAWRKYGQKPIKGSPYPRGYYRCSS . SKGCLARK QVERNRSDEGM IVTYTÄ̈EHNH DSWAWRKYGQKPIKGSPYPRGYYRCSS . .SKGCPARKQVERSSVLESKIVITYSCEHNH DDF SWRKYGCKPIKGSPHPRGYYKCSS . .VRGCPARKHVERALDEFSMLVVTYEGEHNH DGYRWRKYGCKAVKNNKF PRSYYRCTH . . . QGCNVKKQVCRLTKLEGVVVTTYEGMHSH DGNAWRKYGQKEILNANYPRSYYRCTHKYVQDCMATKQVCRMLDEFEKYEITYIGNHTC DGYNWRKYGQKHVKGSEFPRSYYKCTH . . . PNCEVKKKI . .

DGYRWRKYGQKVVKGNENPRSYYKCTS . . . AGCTVRKHVERASHDL LSVITTY. . . . . . . . . . . . DGYRWRKYGCKVVKGNFYPRSYYKCTT . . . TGCNVRKHVERASTLEKKAVITTYEGKHNH DGEKWRKYGKKSVKNNENKRNYYKCSS . . . GGCLVKKRIERDREDSSYVITTYEGTHNH QLNMRSLISNLTLHMIIICRSYYRCSS. . SKGCLARKQVERSSTLFG G F I ITYSAEHNH DGYRWRKYGQKVVKGNPYPRSYYKCTT . . . PGCGVRKHVERAATLEKAVVTTYEGKHNH

\section{a}

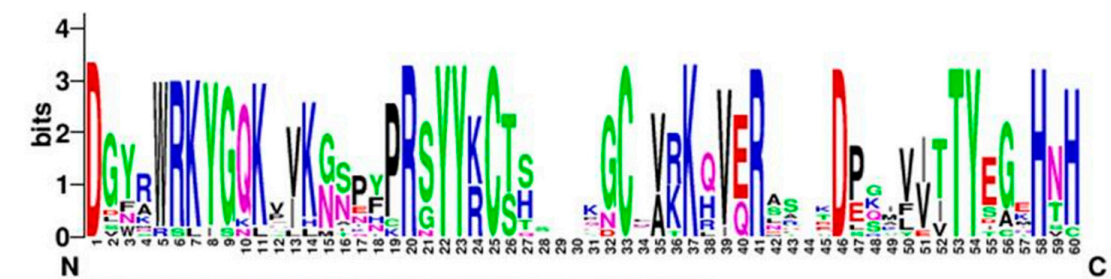

ZbWRKY47

ZbWRKY47_2 ZbWRKY49 ZbWRKY50 ZbWRKY50_2 ZbWRKY20 ZbWRKY51 ZbWRKY74 ZbWRKY7 ZbWRKY15 ZbWRKY7 2 ZbWRKY1 $\overline{7}$ ZbWRKY22 ZbWRKY65 ZbWRKY14 ZbWRKY14_2 Consensus
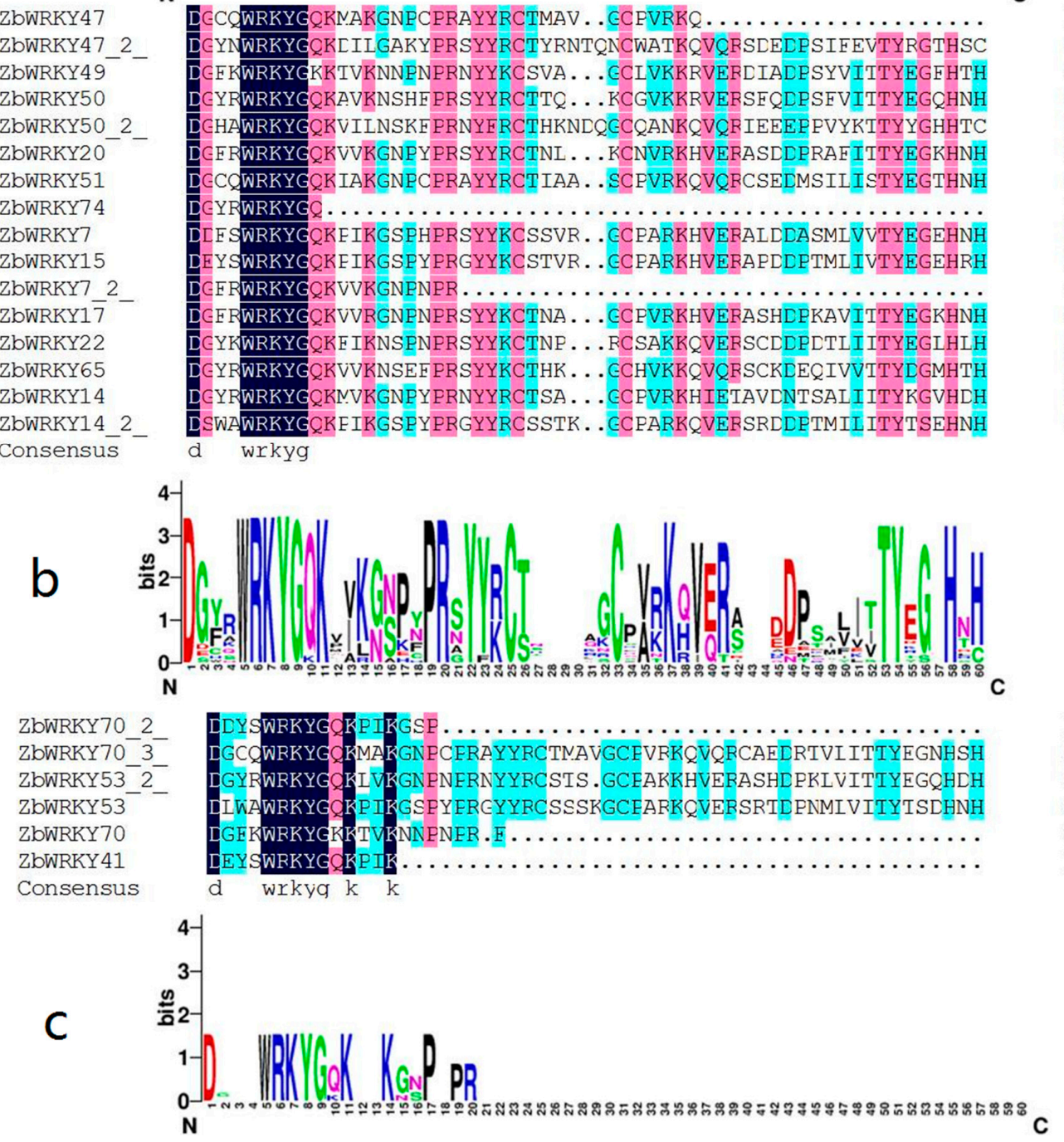

Figure 2. Multiple alignment of WRKY proteins in Zanthoxylum bungeanum: (a) Group I, (b) Group II, and (c) Group III. 


\subsection{Conserved Domain Analysis of ZbKWRKY Gene}

The WRKY domain of the ZbWRKY gene was analyzed by DNAMAN 8.0 sequence analysis software (Lynnon Biosoft, San Ramon, CA, USA) and online software WebLogo 3 (http:/ / weblogo. berkeley.edu/logo.cgi). The results indicate that the WRKYGQK domain of the ZbWRKY gene is highly conserved. ZbWRKY members can be clearly divided into each subfamily, which is consistent with the clustering effect of the Arabidopsis thaliana and Citrus sinensis WRKY transcription factors, which can prove that the classification results of the ZBWRKY family are reliable (Figure 1).

\subsection{ZbWRKY Gene Expression Analysis}

The 38 ZbWRKY genes identified were used for relative quantitative analysis under drought stress. The results show that the $38 \mathrm{ZbWRKY}$ genes had different effects on drought stress (Figure 3).

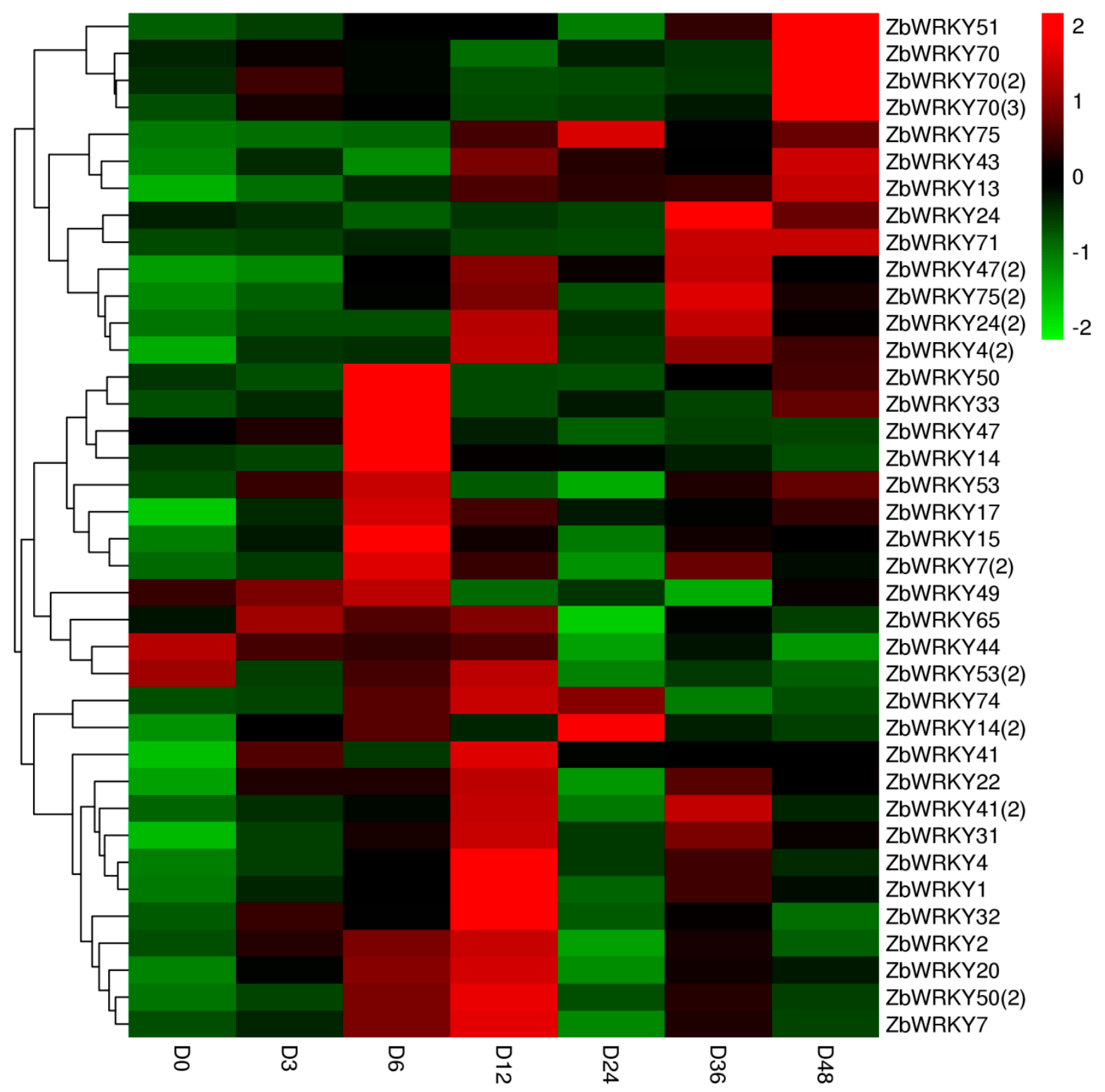

Figure 3. Relative expression heat map of the 38 ZbWRKY genes under drought stress.

Some genes, including WRKY33 and WRKY15, show high levels of expression in the early stages of drought stress. They also respond very rapidly. In contrast, WRKY71 and WRKY51 show significant responses only after $36 \mathrm{~h}$ of stress treatment. Among these, the expression 
levels of ZbWRKY24(2), ZbWRKY71, ZbWRKY70(2), ZbWRKY31, ZbWRKY15, ZbWRKY33, ZbWRKY4, ZbWRKY75(2), ZbWRKY70(3), ZbWRKY4(2), ZbWRKY1, and ZbWRKY51 showed significant upregulation. Generally, the expression levels of the 12 WRKY transcription factors respond significantly to drought, first increasing, then decreasing. This pattern of increase then decrease is consistent with that of gene expression change during drought stress. The relative expression levels of different $Z b W R K Y$ genes under different drought stress time were calculated with reference to the control group D0 (relative expression level defaulted to 1 ). The expression levels were more than 5 -fold those at the D0 (control group) stage. Although the above genes are involved in obvious, corresponding processes for drought, the corresponding times and intensities are quite different. For example, ZbWRKY33 shows high expression at the beginning of the drought stress, more than 30 -fold that at $\mathrm{D} 0$, but it then drops to the control level before rising again to a very high level after $48 \mathrm{~h}$. The corresponding effect of ZbWRKY33 on drought is a phased response. There are many genes whose corresponding patterns are similar, but that differ in times and expression levels such as ZbWRKY24(2), ZbWRKY31, and ZbWRKY75(2). In addition, there are slow responding genes; expressions of $Z b W R K Y 70(2)$ and $Z b W R K Y 71$ remained low in the early stages of drought stress but later showed high levels of expression after treatment for $48 \mathrm{~h}$.

\section{Discussion}

WRKY is one of the important transcription families in plant growth and development. It was first discovered in Ipomoea batatas [4] and has subsequently been found in many plants, including Arabidopsis thaliana [5], rice [6], tomato [7], and cucumber [8]. The WRKY family functions by participating in other signaling pathways to activate the responding genes. The interaction between the ZbWRKY protein and other regulatory proteins was predicted by STRING (http:/ /string-db.org/), a system that searches for interactions between known proteins and predicting proteins. This interaction involved both direct physical interactions between proteins and the correlation of indirect functions between proteins. The relative expression of the gene was detected by real-time PCR. The analysis showed that the relative expression of the 12 ZbWRKY genes was 5-fold higher than the control and there was a significant response relationship. The functional relationship between the $12 \mathrm{ZbWRKY}$ proteins was predicted and analyzed using the STRING protein interaction database. The species selection was the model plant Arabidopsis thaliana.

The 12 transcription factors that responded to drought were input into the STRING website to predict protein interactions. From the protein functional connection network, it can be seen that the WRKY transcription factors have complex interactions with a variety of proteins. Among them, WRKY33, WRKY70, WRKY15, WRKY40, and WRKY25 interact frequently with other proteins, and WRKY33 interacts with WRKY70, WRKY15, WRKY40, WRKY25, MYB51, ERF6, ERF104, salt tolerance zinc finger (STZ), ACS6, MPK3, MPK4, and MKS1, suggesting that these proteins may participate in specific physiological responses and the growth of plants (Figure 4). The results indicated that many members of the ZbWRKY transcription factor family had different responses to drought. For example, the WRKY33 transcription factor was clearly expressed in the early stage of stress, whereas the WRKY71 transcription factor showed significant increases only in the later stages of drought stress. It is inferred that different members of the ZbWRKY transcription factor family play different roles in the overall drought-stress response and exert their various functions in a concerted manner to cope optimally with adverse environments. Thus, the ZbWRKYs and other regulatory substances form a self-defense system. In addition, from the aspect of gene expression, the relative expression of ZbWRKY33 under drought stress was more than 30-fold higher than that of the control, indicating that these proteins play active roles in resisting drought in plants. It can be inferred that it participates in many signaling pathways for self-protection during the time that $Z B$ is subjected to drought. Overexpression of WRKY 25 or WRKY33 can greatly increase $\mathrm{NaCl}$ tolerance in Arabidopsis and increases the sensitivity to ABA [20]. In addition, WRKY33 has been shown to be an important transcription factor in pathogen defense, modulating the 
antagonistic relationship between defense pathways that mediate responses to Pseudomonas syringae and necrotrophic pathogens [21,22]. The ectopic expression of the Gossypium hirsutum WRKY6 gene significantly increased the salt tolerance of Arabidopsis thaliana, whereas the silencing of the GhWRKY6 gene increased the sensitivity to abiotic stress in cotton [13].
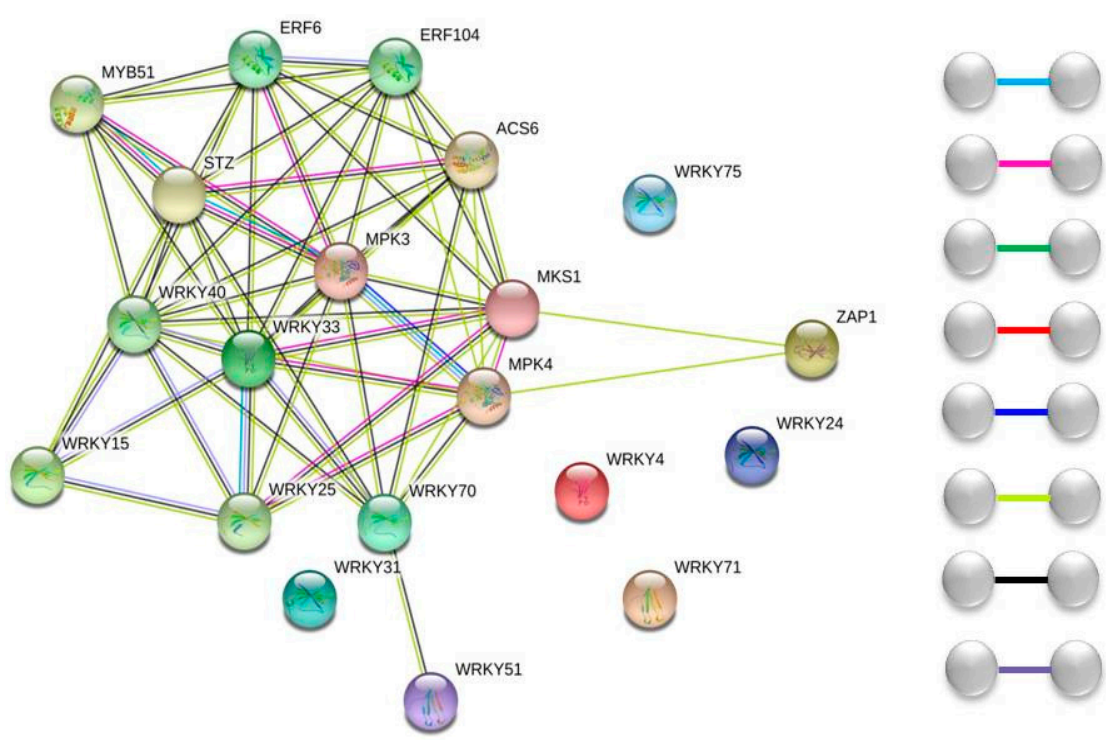

From curated databases

Experimentally determined

Gene neighborhood

Gene fusions

Gene co-occurrence

Textmining

Co-expression

Protein homology

Figure 4. The WRKY protein functional connection network.

The MAPK signaling pathway, the JA signaling pathway, the SA signaling pathway, and the ethylene signal pathway are also important signal pathways involved in plant responses to adverse environments. Multiple protein interactions reveal that multiple signaling pathways, such as the MAPK signaling pathways, are involved in drought stress. MPK3 has been shown to function as a phosphorylated WRKY protein and is involved in the MAPK signaling pathway [23]. WRKY25 and WRKY33 transcription factors act downstream of MPK4-mediated signaling and contribute to plant resistance [24]. In the MPK4-WRKY33 double mutant, the inhibition of PAD3 expression further supports the view that WRKY33 is an effector of MPK4 [25]. MKS1 is a regulatory protein of plant defense responses. The coupling activation of MPK4 regulation may be facilitated by coupling a kinase to a specific WRKY transcription factor [25]. Mitogen-activated protein kinase (MAPK) cascade, MAPK kinase 3 (MKK3)-MAPK 6 (MPK6), is activated by JA in Arabidopsis and is capable of inducing downstream wounding stress response genes (Figure 5) [26]. In addition, studies have shown that the MKK2 pathway plays a positive role in increasing plant resistance under salt stress [27]. At the same time, external stress signals can also stimulate receptors on the cell membrane to activate the MAPK signaling pathway [28].

Co-expression analysis indicates that the ZbWRKY transcription factor family has interplaying effects on plant growth and developmental processes as well as being involved in biotic and abiotic stress responses and participating in signal transduction in multiple signaling pathways including ethylene, ABA, JA, and SA. Plant survival depends on the twin abilities of rapid perception and rapid response, and these are regulated primarily by the JA signaling pathway $[29,30]$. From analysis of the ZbWRKY expression, it also has very frequent interaction with the JA signaling pathway. For example, WRKY70 is an important node of JA- and SA-mediated plant resistance and acts as an activator of the SA-inducible gene and a suppressor of the JA-responsive gene to integrate these two signals that mediate the mutual resistance of plants [31]. Salt tolerance zinc finger (STZ) transcriptional repressors are involved in abiotic stress responses and can inhibit the stress response genes DREB1A and LTI78. In addition, STZ may also be involved in the early signal response of JA, regulate the expression of the JA biosynthesis gene LOX3, and control the expression of TIFY10A/JAZ1, which is a key repressor in the JA signaling cascade [32,33]. Moreover, MYC2 is a major positive regulator of JA gene expression 
and is capable of binding to the G-box region upstream of the JA gene to increase gene expression level [34]. The activation of the ABA/JA pathway also promotes plant drought tolerance by reducing transpiration, reducing stomatal opening, and inhibiting growth retardation factors [35]. These two signaling pathways have some common components in the guard cells; cADPR and cGMP are the second messenger in the ABA-induced stomatal closure signaling pathway. Studies have found that cADPR and cGMP also play the same role in JA-mediated stomatal closure [36].

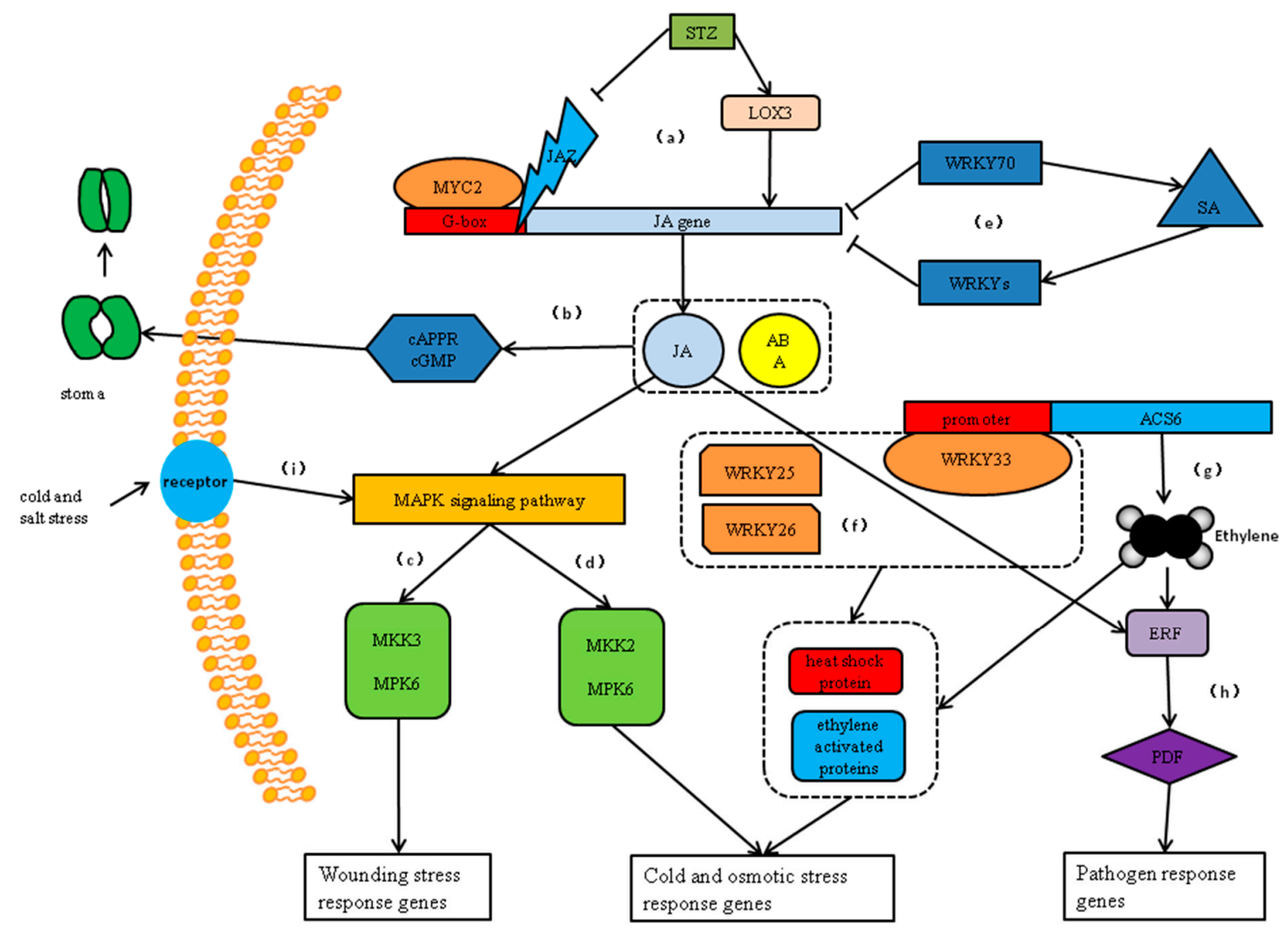

Figure 5. The stress signal path model of WRKY participation. (a) MYC2 is a major positive regulator of JA gene expression and is capable of binding to the G-box region upstream of the JA gene to increase gene expression levels. JAZ can suppress the combination of MYC2 and G-box area, and salt tolerance zinc finger (STZ) is involved in the early signaling response of JA and regulates the expression of the JA synthetic gene LOX3. (b) The JA/ABA signaling pathway regulates the second messenger cAPPR and cGMP to close stomata. (c) The mitogen-activated protein kinase (MAPK) cascade, MAPK kinase 3 (MKK3)-MAPK 6 (MPK6), is activated by JA in Arabidopsis and is capable of inducing downstream wounding stress response genes. (d) MPK6 activation by MEKK1 is mediated by MKK2. MKK2-MPK6 cascades mediate cold and salt stress tolerance in plants. (e) WRKY70 can inhibit the expression of the $J A$ gene and activate the SA signaling pathway to induce more WRKY transcription factors to inhibit JA. (f) WRKY25, WRKY26, and WRKY33 transcription factors interact to regulate cooperation between ethylene-activated protein- and heat shock protein-related signaling pathways. (g) ACS6 is a synthetic precursor of ethylene, and WRKY33 binds directly to the promoters of ACS2 and ACS6 to promote gene expression. (h) ERF can be activated by ethylene and act on PDF (plant defensin) to activate downstream pathogen response genes, which can also be regulated by JA. (i) When the receptor receives signals of cold or osmotic stress, it will stimulate the MAPK signal pathway and thus improve plant resistance.

The WRKY transcription factors are also closely related to the ethylene signaling pathway. ACS6 (1-aminocyclopropane-1-carboxylate synthase 6) is a synthetic precursor of ethylene, and WRKY33 has been shown to bind directly to the promoters of ACS2 and ACS6 to alter 
gene expression in Arabidopsis [37]. ERF6 (ethylene-responsive transcription factor 6) may be a transcriptional activator that binds to the GCC-box pathogenesis-related promoter element. It may be involved in the regulation of gene expression by components of stress factors and stress signal transduction pathways. Moreover, SA can induce the degradation of ERF transcription factor ORA59 and activate the JA signaling pathway at the same time. In addition, SA negatively regulates WRKY transcription factors and directly or indirectly inhibits JA response gene expression [38].

From the above analysis, there is a close relationship between STZ, MYB51, MPK3, MPK4, and ERF6. It can be inferred that external stresses stimulate the internal regulation system of organisms including WRKY, and also activate a large number of functional proteins and transcription factors involved in plant stress resistance. Among the many ZbWRKYs, ZbWRKY33 is especially worthy of attention. WRKY33 responded significantly to the drought stress of $Z B$, and it was also demonstrated in other studies that it promoted plant drought resistance. Studies have shown that WRKY25, WRKY26, and WRKY33 regulate the cooperation between ethylene-activated protein- and heat shock protein-related signaling pathways, which mediate the response to heat stress. These three proteins interact functionally and play overlapping and synergistic roles in heat resistance in plants [39]. In addition, studies have shown that pathogens can induce the expression of WRKY33 transcription factors, thereby activating the defense pathway and antagonizing the pathogens [21]. In general, WRKY33 participates in many biological activities and plays different roles with different protein interactions, forming a WRKY33-based anti-stress control system, and playing an especially prominent role in resisting external adversity.

Transcription factors respond to stress and participate in the regulation of numerous signaling pathways. They also produce protective substances that help to combat adverse environments. Previous studies have found that the transgenic wheat TaWRKY93 gene Arabidopsis thaliana accumulates more SOD and POD than wild-type Arabidopsis This indicates that transgenic plants reduce cell membrane damage and increase intracellular antioxidant enzymes during drought [40]. Both drought stress and salt stress are osmotic stresses. These two stresses produce many similar results, such as stomatal closure, increased antioxidants, and increased water retention. Based on the important role of the WRKY family in drought resistance, disease resistance, and other roles, it is important to consider overexpression of certain members of the resistant WRKY family when seeking to improve the resistance characteristics of plants.

\section{Materials and Methods}

\subsection{Materials}

Three-month-old Chinese prickly ash seedlings (Fengxian Zanthoxylum bungeanum test station, Baoji, China) were selected for uniformity. The seedlings were cultivated in the environmental-controlled greenhouses of Northwest Agriculture and Forestry University (Xianyang, China). The culture conditions were a temperature of $25 \pm 3^{\circ} \mathrm{C}$ and a light intensity of $2000 \mathrm{~lx}, 12 \mathrm{~h} \mathrm{light/day.} \mathrm{Half-strength} \mathrm{Murashige}$ and Skoog (MS) medium with additions of polyethylene glycol (PEG) 6000 to $20 \%$ was used as the drought-stress treatment. Seven treatment times were employed: $0 \mathrm{~h}$ (D0), $3 \mathrm{~h}$ (D3), $6 \mathrm{~h}$ (D6), $12 \mathrm{~h}$ (D12), $24 \mathrm{~h}$ (D24), $36 \mathrm{~h}$ (D36), and $48 \mathrm{~h}$ (D48). The leaves were collected and each treatment combination was replicated three times. The samples collected were promptly stored in liquid nitrogen pending analysis. Samples of the compounds are available from the authors.

Transcriptome sequencing materials of Zanthoxylum bungeanum were collected from the Experimental Station of Northwest Agriculture and Forestry University in Fengxian, Shaanxi, China. The $Z b$ skins were collected and quickly immersed in liquid nitrogen and stored at $-80^{\circ} \mathrm{C}$ pending use for transcriptome sequencing. From the transcriptome of the Zb skin (unpublished), the ZbWRKY transcription factor was initially obtained based on the annotation information. The WRKY transcription factor was confirmed by the SMART website (http:/ / smart.embl-heidelberg.de/smart/ 
set_mode.cgi?NORMAL=1) and the HMMER website (https://www.ebi.ac.uk/Tools/hmmer/) and the sequence of $38 \mathrm{Z} b$ WRKY transcription factors was then obtained.

\subsection{Methods}

\subsubsection{Total RNA Extraction and Reverse Transcription}

The total RNA of the sample is extracted using the TaKaRa MiniBEST Plant RNA Extraction Kit (TaKaRa, Beijing, China) and extracted and purified according to the instructions. The obtained sample total RNA was tested for its concentration and purity using NanoDrop 20000 (Thermo Scientific, Pittsburgh, PA, USA). Only RNA samples with $\mathrm{OD}_{260 / 280}$ ratios between 1.8 and 2.2 and $\mathrm{OD}_{260 / 230}$ ratios higher than 2.0 were used for subsequent experiments.

\subsubsection{Bioinformatics Analysis}

MEGA 7.0 (Center for Evolutionary Medicine and Informatics, Tempe, AZ, USA) was used in the phylogenetic tree analysis of the WRKY protein sequences of the $Z B$ and the WRKY protein sequences of Arabidopsis thaliana [41]. The set parameters were as follows: Poisson correction, pairwise deletion, and bootstrap (1000 repetitions). Meanwhile, 35 Arabidopsis WRKY protein sequences were introduced to subclass ZbWRKY. The Arabidopsis WRKY protein sequences were downloaded from the Arabidopsis website (http:/ / www.arabidopsis.org/), and Citrus sinensis WRKY protein sequences were downloaded from the PlantTFDB website (http://planttfdb.cbi.pku.edu.cn/). The analysis of the heat map was carried out using the OmicShare website (http:/ /www.omicshare.com/).

\subsubsection{Identification and Screening of Transcription Factor Family Genes}

According to the annotation information of transcriptome data, ZbWRKY transcription factors were preliminarily screened out, then BLAST confirmation was carried out according to the conservative structural domain of WRKY, and 38 sequences satisfying the requirements were finally confirmed from 50 transcription factors.

\subsubsection{Real-Time qPCR}

All primers were designed using Primer 5.0 (Premier, Palo Alto, CA, USA) and the primers for the sequences are listed in Table 2. To obtain the expression pattern of the WRKY family gene under drought stress, CFX96 Real-Time PCR Detection System (Bio-Rad, Hercules, CA, USA) was used to detect gene expression levels. Each $10 \mu \mathrm{L}$ reaction used $5 \mu \mathrm{L}$ of $2 \times$ SYBR Premix Ex Taq II (TaKaRa, Beijing, China), $1 \mu \mathrm{L}$ of cDNA, $1 \mu \mathrm{L}$ of each of the forward and reverse primers and $3 \mu \mathrm{L}$ of $\mathrm{ddH}_{2} \mathrm{O}$. RT-qPCR amplifications were carried out using the program: $95^{\circ} \mathrm{C}$ for $30 \mathrm{~s}$ followed by 40 cycles of $94{ }^{\circ} \mathrm{C}$ for $5 \mathrm{~s}, 54{ }^{\circ} \mathrm{C}$ for $30 \mathrm{~s}$, and $72{ }^{\circ} \mathrm{C}$ for $45 \mathrm{~s}$. To accurately measure the relative expression level of genes, $1 \mathrm{ng}$ of cDNA was added to each fluorescent quantitative PCR reaction system.

ZbUBQ was used as a reference gene to calculate the relative expressions of the WRKY family genes [42]. The cycle threshold values (Ct) of all samples were collected by the CFX96 Real-Time PCR Detection System, and gene relative expression was calculated as follows: relative expression, that is, $2^{-\Delta \Delta C t}$. 
Table 2. Primers for real-time quantitative PCR.

\begin{tabular}{|c|c|c|c|c|c|c|}
\hline Number & Name & $\mathbf{F} / \mathbf{R}$ & Primer Sequences & $\operatorname{Tm}$ & Product Length & $\begin{array}{l}\text { Homologous Sequence of } \\
\text { Arabidopsis thaliana }\end{array}$ \\
\hline \multirow{2}{*}{1} & \multirow{2}{*}{ ZbWRKY43 } & $\mathrm{F}$ & TTCAGCTTCCCAGTTCTCATT & 56.6 & \multirow{2}{*}{144} & \multirow{2}{*}{ KDO64417.1 } \\
\hline & & $\mathrm{R}$ & TGTTTCACCTTATCATTACTCCC & 55.8 & & \\
\hline \multirow{2}{*}{2} & \multirow{2}{*}{ ZbWRKY13 } & $\mathrm{F}$ & TTTTCAGCTTCCCAGTTCTCA & 57.6 & \multirow{2}{*}{146} & \multirow{2}{*}{ XP_006464513.1 } \\
\hline & & $\mathrm{R}$ & TGTTTCACСТTATCATTACTCСС & 55.8 & & \\
\hline \multirow{2}{*}{3} & \multirow{2}{*}{ ZbWRKY47 } & $\mathrm{F}$ & AGAAGCGAGTAACCTTAAAGTAGA & 54.7 & \multirow{2}{*}{203} & \multirow{2}{*}{ XP_006492428.1 } \\
\hline & & $\mathrm{R}$ & TGACATTCAATGCAGCAGAT & 54.3 & & \\
\hline \multirow{2}{*}{4} & \multirow{2}{*}{ ZbWRKY75 } & $\mathrm{F}$ & GATGATGGTTATAGATGGAGGA & 53.5 & \multirow{2}{*}{202} & \multirow{2}{*}{ XP_006436871.1 } \\
\hline & & $\mathrm{R}$ & GTTCAAAGCTGTCAGTGAGTTT & 54 & & \\
\hline \multirow{2}{*}{5} & \multirow{2}{*}{ ZbWRKY41 } & $\mathrm{F}$ & GAGCAATCTGGACTTTGAGGGA & 60.8 & \multirow{2}{*}{186} & \multirow{2}{*}{ XP_011022522.1 } \\
\hline & & $\mathrm{R}$ & CCAAGAATGTCTTTTTGACCGT & 58.7 & & \\
\hline \multirow{2}{*}{6} & \multirow{2}{*}{ ZbWRKY74 } & $\mathrm{F}$ & CAAGCACTTTGTCATCAACTAA & 53.5 & \multirow{2}{*}{158} & \multirow{2}{*}{ KDO54401.1 } \\
\hline & & $\mathrm{R}$ & АСТСССАGAАTСТTСТССТСТG & 56.8 & & \\
\hline \multirow{2}{*}{7} & \multirow{2}{*}{ ZbWRKY24 } & $\mathrm{F}$ & TCATССТАAGССТСААТСТАСС & 55.7 & \multirow{2}{*}{212} & \multirow{2}{*}{ XP_006431962.1 } \\
\hline & & $\mathrm{R}$ & ATTTACTCCTCTGTGATCCCTG & 55.3 & & \\
\hline \multirow{2}{*}{8} & \multirow{2}{*}{ ZbWRKY24(2) } & $\mathrm{F}$ & CAACAAAGAAGAAAGTGGAGAGG & 57.9 & \multirow{2}{*}{135} & XP 006431962.1 \\
\hline & & $\mathrm{R}$ & GGATGGCATTAGAATTAACCGAA & 60.5 & & \\
\hline 9 & ZbWRKY22 & $\mathrm{F}$ & GAAACAAGTGGAGCGAAACAGA & 59.6 & 206 & XP_006444950.1 \\
\hline & & $\mathrm{R}$ & CCGGAGATGAGGAAGAGAAAGT & 59.3 & & \\
\hline 10 & ZbWRKY70 & $\mathrm{F}$ & TGAAGATGGTCATGGATGGAGA & 59.9 & 62 & XP_006435943.1 \\
\hline & & $\mathrm{R}$ & TTGGATATTTAGCATTGCGGAT & 59.5 & & \\
\hline 11 & ZbWRKY49 & $\mathrm{F}$ & GGCTTCATCTCCACTTTGСТTAC & 60.1 & 87 & XP_006480891.1 \\
\hline & & $\mathrm{R}$ & TGGTCTTTTTTGGTTTCTTTGTT & 58.1 & & \\
\hline 12 & ZbWRKY50 & $\mathrm{F}$ & CATTTTCGGGGCTGTTCATA & 58.6 & 122 & XP_006474455.1 \\
\hline & & $\mathrm{R}$ & ССТСТСССТСССАСТТТСАТ & 57.9 & & \\
\hline 13 & ZbWRKY50(2) & $\mathrm{F}$ & TATGGGAAGAAGACGGTGAA & 55.4 & 156 & XP_006474454.1 \\
\hline & & $\mathrm{R}$ & ATTGCTTTGGTGAGTGTGGA & 55.9 & & \\
\hline 14 & ZbWRKY71 & $\mathrm{F}$ & GAAGATGGGTATCGGTGGA & 55 & 189 & KDO78100.1 \\
\hline & & $\mathrm{R}$ & CAAGGTTGTGGGAAGTGGA & 56 & & \\
\hline
\end{tabular}


Table 2. Cont.

\begin{tabular}{|c|c|c|c|c|c|c|}
\hline Number & Name & $\mathbf{F} / \mathbf{R}$ & Primer Sequences & $\operatorname{Tm}$ & Product Length & $\begin{array}{c}\text { Homologous Sequence of } \\
\text { Arabidopsis thaliana }\end{array}$ \\
\hline \multirow{2}{*}{15} & \multirow{2}{*}{ ZbWRKY70(2) } & $\mathrm{F}$ & AAATCTCATTCATAAGTCCAC & 56.4 & \multirow{2}{*}{262} & \multirow{2}{*}{ XP_006481203.1 } \\
\hline & & $\mathrm{R}$ & GCTTCTGATAATCTTCССАAC & 53.4 & & \\
\hline \multirow{2}{*}{16} & \multirow{2}{*}{ ZbWRKY65 } & $\mathrm{F}$ & TTCAAAAGCCGCCAAGACC & 61 & \multirow{2}{*}{153} & \multirow{2}{*}{ XP_006467614.1 } \\
\hline & & $\mathrm{R}$ & TCCATTTCCCCAAACCACG & 61.1 & & \\
\hline \multirow{2}{*}{17} & \multirow{2}{*}{ ZbWRKY7 } & $\mathrm{F}$ & TGCCTCСТTTGССТСТССА & 61.2 & \multirow{2}{*}{147} & \multirow{2}{*}{ KDO84087.1 } \\
\hline & & $\mathrm{R}$ & CGCTGTCAGTATCCCCTGC & 58.6 & & \\
\hline \multirow{2}{*}{18} & \multirow{2}{*}{ ZbWRKY31 } & $\mathrm{F}$ & AAAGGAAATGGTAAACGAGG & 54 & \multirow{2}{*}{222} & \multirow{2}{*}{ KDO54715.1 } \\
\hline & & $\mathrm{R}$ & TCTGAAGAAGAAAGCGAAGG & 55 & & \\
\hline \multirow{2}{*}{19} & \multirow{2}{*}{ ZbWRKY15 } & $\mathrm{F}$ & GATTGTCTGACATCCCACC & 52 & \multirow{2}{*}{147} & \multirow{2}{*}{ XP_006425967.1 } \\
\hline & & $\mathrm{R}$ & CATCCAAAGCTCTCTCCAC & 52.2 & & \\
\hline \multirow{2}{*}{20} & \multirow{2}{*}{ ZbWRKY7(2) } & $\mathrm{F}$ & GGAGAAAGTACGGACAGAAACC & 57.4 & \multirow{2}{*}{136} & \multirow{2}{*}{ XP_006494483.1 } \\
\hline & & $\mathrm{R}$ & GTGACAACAAGCATTGATGGAT & 57.4 & & \\
\hline \multirow{2}{*}{21} & \multirow{2}{*}{ ZbWRKY17 } & $\mathrm{F}$ & AACGGGAAGCAAGGAGGAT & 58.5 & \multirow{2}{*}{91} & \multirow{2}{*}{ XP_006483548.1 } \\
\hline & & $\mathrm{R}$ & TGTACGGCTGAGAGGCGAG & 59.4 & & \\
\hline \multirow{2}{*}{22} & \multirow{2}{*}{ ZbWRKY33 } & $\mathrm{F}$ & СТTССТССТGTTСССССТTСТ & 61.2 & \multirow{2}{*}{257} & XP 012089749.1 \\
\hline & & $\mathrm{R}$ & CGTGGTTCCTGTTGCCTCTTA & 60.3 & & \\
\hline 23 & ZbWRKY4 & $\mathrm{F}$ & ACTTGTTTTCCATCCGTCAC & 54.6 & 158 & XP 006482724.1 \\
\hline & 20 & $\mathrm{R}$ & CCATCATCAGCAGGTTTGTC & 55.8 & & \\
\hline 24 & ZbWRKY53 & $\mathrm{F}$ & TССТТТСССААСАСТАСАССАA & 59.6 & 116 & XP 006491244.1 \\
\hline & & $\mathrm{R}$ & AGAGTCCAGCCGACCTTTACAT & 59.7 & & \\
\hline 25 & ZbWRKY75(2) & $\mathrm{F}$ & ATAATAAGTGGGGTTCTTTTGGTT & 58.1 & 132 & AFO315151 \\
\hline & & $\mathrm{R}$ & GTTGTTGTTGATGTTGTAGTGGTG & 57.4 & & \\
\hline 26 & ZbWRKY $70(3)$ & $\mathrm{F}$ & TCCCAACAGAAGTGAAACAAG & 55.2 & 95 & KDO675511 \\
\hline & & $\mathrm{R}$ & CACAAAATCCTCССАСАТАAT & 54.3 & & \\
\hline 27 & ZbWRKY14 & $\mathrm{F}$ & CCATGTGATTCACCAGTGACG & 59.1 & 249 & XP_006448817.1 \\
\hline & & $\mathrm{R}$ & TCCAGTAGACCTGCTGTTTGC & 57.9 & & \\
\hline 28 & ZbWRKY20 & $\mathrm{F}$ & ACTGAGGTTCGAGTGGGTGAC & 58.6 & 229 & XP 006452514.1 \\
\hline & & $\mathrm{R}$ & СTGCCTGAGGCTTAAAAAAGG & 59 & & \\
\hline
\end{tabular}


Table 2. Cont.

\begin{tabular}{|c|c|c|c|c|c|c|}
\hline Number & Name & $F / R$ & Primer Sequences & $\operatorname{Tm}$ & Product Length & $\begin{array}{c}\text { Homologous Sequence of } \\
\text { Arabidopsis thaliana }\end{array}$ \\
\hline \multirow{2}{*}{29} & \multirow{2}{*}{$Z b W R K Y 47(2)$} & $\mathrm{F}$ & ТССАТТТСССАССАТТАССС & 59.4 & \multirow{2}{*}{122} & \multirow{2}{*}{ XP_006444621.1 } \\
\hline & & $\mathrm{R}$ & ATGAAGCATGTCGTTGCCTT & 58 & & \\
\hline \multirow{2}{*}{30} & \multirow{2}{*}{ ZbWRKY32 } & $\mathrm{F}$ & ACCAAACAACTTCAACCCAGT & 56.2 & \multirow{2}{*}{135} & \multirow{2}{*}{ XP_006453624.1 } \\
\hline & & $\mathrm{R}$ & AAGGCTTTATTTCAAACCCGA & 58.7 & & \\
\hline \multirow{2}{*}{31} & \multirow{2}{*}{ ZbWRKY44 } & $\mathrm{F}$ & САСССААААССТСААССТССТА & 60.8 & \multirow{2}{*}{292} & \multirow{2}{*}{ XP_006428919.1 } \\
\hline & & $\mathrm{R}$ & ТТССТТСАТСАСАТТССССАСТ & 60.8 & & \\
\hline \multirow{2}{*}{32} & \multirow{2}{*}{ ZbWRKY53(2) } & $\mathrm{F}$ & TTTTTAGGGGGTTTCTCCTC & 55.5 & \multirow{2}{*}{162} & \multirow{2}{*}{ XP_006439376.1 } \\
\hline & & $\mathrm{R}$ & GGCATTTGAATTATTGGCTG & 56 & & \\
\hline \multirow{2}{*}{33} & \multirow{2}{*}{ ZbWRKY2 } & $\mathrm{F}$ & AGACAGCCTCAGCCTCCAAAC & 60.8 & \multirow{2}{*}{183} & \multirow{2}{*}{ XP_006474751.1 } \\
\hline & & $\mathrm{R}$ & TCCTCAGATGATGCACCTCCA & 60.9 & & \\
\hline \multirow{2}{*}{34} & \multirow{2}{*}{ ZbWRKY4(2) } & $\mathrm{F}$ & ATCCGCCACCTCAATCTAA & 55.2 & \multirow{2}{*}{201} & \multirow{2}{*}{ KDO83046.1 } \\
\hline & & $\mathrm{R}$ & CAGCATCACССССТTCTTC & 57.4 & & \\
\hline \multirow{2}{*}{35} & \multirow{2}{*}{ ZbWRKY1 } & $\mathrm{F}$ & GCTGTTGGAATTGTCGTGTCT & 57.5 & \multirow{2}{*}{81} & \multirow{2}{*}{ XP_006447745.1 } \\
\hline & & $\mathrm{R}$ & ATCGGATGATTTGTCTTTGGC & 59.1 & & \\
\hline \multirow{2}{*}{36} & \multirow{2}{*}{ ZbWRKY41(2) } & $\mathrm{F}$ & AACGAAGAAACGAAATACAACA & 55 & \multirow{2}{*}{234} & \multirow{2}{*}{ XP_006490540.1 } \\
\hline & & $\mathrm{R}$ & CCTATCAGAAGGACAAACAACA & 54.7 & & \\
\hline \multirow{2}{*}{37} & \multirow{2}{*}{ ZbWRKY51 } & $\mathrm{F}$ & ATCTTGAAGTAATGGATGATGGA & 55.8 & 73 & XP 006464492.1 \\
\hline & & $\mathrm{R}$ & TTATTTGGGTTGTTCTTGACTGA & 57.1 & & \\
\hline 38 & ZbWRKY14(2) & $\mathrm{F}$ & GCAAGGAAACAAGTGGAACG & 58.1 & 214 & KDO763421 \\
\hline & & $\mathrm{R}$ & ACTCATCATCAATGGCGGTC & 57.7 & & \\
\hline UBO & Ubiquitin & $\mathrm{F}$ & TCGAAGATGGCCGTACATTG & 57.5 & 122 & - \\
\hline & extension protein & $\mathrm{R}$ & ТССТСТААGССТСАGСАССА & 59.5 & & \\
\hline
\end{tabular}

F: Forward primer; R: Reverse primer. 


\section{Conclusions}

Thirty-eight WRKY transcription factors were identified and isolated from $Z B$. WRKY transcription factors were divided into three groups (Groups I, II, and III) according to the conserved sequence of transcription factors and the family classification of Arabidopsis thaliana-of the 38 WRKY transcription factors, 15 were in Group I, 16 in Group II, and 7 in Group III.

The relative expression levels of 38 transcription factors under drought stress induced by PEG 6000 were detected using real-time PCR. All transcription factors responded differently to drought stress, and $12 \mathrm{ZbWRKY}$ transcription factors were significantly up-regulated. These results suggest that these transcription factors may be involved in the drought-resistant process of $Z B$. Protein interaction analysis of the responding genes was carried out on the STRING website. Arabidopsis thaliana was selected as the predicted species. The results of the interaction analysis indicate that the WRKY transcription factor family is widely involved in the transmission of plant stress signals and is closely related to the JA signaling pathway, the MAPK signaling pathway, the ethylene signaling pathway, and the ABA signaling pathway. ZbWRKY33 is a homologous sequence of Arabidopsis thaliana WRKY33, which is the most intense transcription factor in response to drought stress (the relative expression level is more than 30-fold higher than that of the control group). WRKY33 is able to bind directly to the ethylene synthesis precursor gene ACS6, to promote ethylene synthesis. Subsequently, ethylene binds to the ethylene-activated protein release signal to activate a series of downstream cold-stress and osmotic-stress response genes, suggesting that ZbWRKY33 has a similar function in ZB. The JA signaling pathway plays an important role in plant stress signaling. The role of ZbWRKY transcription factors in drought stress relies on a regulatory network center in the JA signaling pathway. Based on the known functions of transcription factors such as ZbWRKY33, these transcription factors can be used as candidate genes for drought-resistance breeding.

Author Contributions: A.W. conceived the project. X.F. designed the experiments and performed the experiment. X.F. wrote the paper. All authors (X.F., L.H., J.S., T.Y., Y.L., and A.W.) discussed the results and commented on the manuscript.

Funding: This study was financially supported by the National Key Research and Development Program Project Funding (2018YFD1000605).

Acknowledgments: The authors would like to thank Yao Ma for his participation in the manuscript discussion.

Conflicts of Interest: The authors declare no conflict of interest.

\section{References}

1. Schwechheimer, C.; Zourelidou, M.; Bevan, M.W. Plant transcription factor studies. Annu. Rev. Plant Biol. 1998, 49, 127-150. [CrossRef] [PubMed]

2. Riechmann, J.L.; Ratcliffe, O.J. A genomic perspective on plant transcription factors. Curr. Opin. Plant Biol. 2000, 3, 423-434. [CrossRef]

3. Ulker, B.; Somssich, I.E. WRKY transcription factors: From DNA binding towards biological function. Curr. Opin. Plant Biol. 2004, 7, 491-498. [CrossRef] [PubMed]

4. Ishiguro, S.; Nakamura, K. Characterization of a cDNA encoding a novel DNA-binding protein, SPF1, that recognizes SP8 sequences in the $5^{\prime}$ upstream regions of genes coding for sporamin and $\beta$-amylase from sweet potato. Mol. Gen. Genet. 1994, 224, 563-571. [CrossRef]

5. Dong, J.; Chen, C.; Chen, Z. Expression profiles of the ArabidopsisWRKY gene superfamily during plant defense response. Plant Mol. Biol. 2003, 51, 21-37. [CrossRef] [PubMed]

6. Zhang, Z.L.; Xie, Z.; Zou, X.; Casaretto, J.; Ho, T.H.; Shen, Q.J. A rice WRKY gene encodes a transcriptional repressor of the gibberellin signaling pathway in aleurone cells. Plant Physiol. 2004, 134, 1500-1513. [CrossRef] [PubMed]

7. Huang, S.; Gao, Y.; Liu, J.; Peng, X.; Niu, X.; Fei, Z.; Cao, S.; Liu, Y. Genome-wide analysis of WRKY transcription factors in Solanum lycopersicum. Mol. Genet. Genom. 2012, 287, 495-513. [CrossRef] [PubMed]

8. Ling, J.; Jiang, W.; Zhang, Y.; Yu, H.; Mao, Z.; Gu, X.; Huang, S.; Xie, B. Genome-wide analysis of WRKY gene family in Cucumis sativus. BMC Genom. 2011, 12, 471. [CrossRef] [PubMed] 
9. Ciolkowski, I.; Wanke, D.; Birkenbihl, R.P.; Somssich, I.E. Studies on DNA-binding selectivity of WRKY transcription factors lend structural clues into WRKY-domain function. Plant Mol. Biol. 2008, 68, 81-92. [CrossRef] [PubMed]

10. Weng, S.; Cocivera, M. Identification of novel pathogen-responsive cis-elements and their binding proteins in the promoter of OsWRKY13, a gene regulating rice disease resistance. Plant Cell Environ. 2010, 31, 86-96.

11. Zhang, C.-Q.; Xu, Y.; Lu, Y.; Yu, H.-X.; Gu, M.-H.; Liu, Q.-Q. The WRKY transcription factor OsWRKY78 regulates stem elongation and seed development in rice. Planta 2011, 234, 541-554. [CrossRef] [PubMed]

12. Şahin-Çevik, M. A WRKY transcription factor gene isolated from Poncirus trifoliata shows differential responses to cold and drought stresses. Plant Omics 2012, 5, 438-445.

13. Ullah, A.; Sun, H.; Hakim; Yang, X.; Zhang, X. A novel cotton WRKY gene, GhWRKY6-like, improves salt tolerance by activating the ABA signaling pathway and scavenging of reactive oxygen species. Physiol. Plant 2018, 162, 439-454. [CrossRef] [PubMed]

14. Huh, S.U.; Choi, L.M.; Lee, G.J.; Kim, Y.J.; Paek, K.H. Capsicum annuum WRKY transcription factor d (CaWRKYd) regulates hypersensitive response and defense response upon Tobacco mosaic virus infection. Plant Sci. 2012, 197, 50-58. [CrossRef] [PubMed]

15. Liu, L.; Zhang, Z.; Dong, J.; Wang, T. Overexpression of MtWRKY76 increases both salt and drought tolerance in Medicago truncatula. Environ. Exp. Bot. 2016, 123, 50-58. [CrossRef]

16. Zhao, J.; Zhang, X.; Guo, R.; Wang, Y.; Guo, C.; Li, Z.; Chen, Z.; Gao, H.; Wang, X. Over-expression of a grape WRKY transcription factor gene, VIWRKY48, in Arabidopsis thaliana increases disease resistance and drought stress tolerance. Plant Cell Tissue Organ Cult. 2017, 132, 359-370. [CrossRef]

17. Ding, Z.J.; Yan, J.Y.; Xu, X.Y.; Yu, D.Q.; Li, G.X.; Zhang, S.Q.; Zheng, S.J. Transcription factor WRKY46 regulates osmotic stress responses and stomatal movement independently in Arabidopsis. Plant J. 2014, 79, 13-27. [CrossRef]

18. Huang, D.M.; Zhao, G.H.; Chen, Z.D.; Kan, J.Q. The food culture of Chinese prickly ash. China Condiment 2006, 75-81.

19. Shuming, L.; Jiaqian, S.; Zhenyi, D.; Diandian, W.; Gang, Z.; Bingyin, S. Effects of Drought Stress on the Root Morphology and Water Use Efficiency of Zanthoxylum bungeanum. Sci. Silvae Sin. 2013, 49, 30-35.

20. Jiang, Y.; Deyholos, M.K. Functional characterization of Arabidopsis NaCl-inducible WRKY25 and WRKY33 transcription factors in abiotic stresses. Plant Mol. Biol. 2009, 69, 91-105. [CrossRef]

21. Zheng, Z.; Qamar, S.A.; Chen, Z.; Mengiste, T. Arabidopsis WRKY33 transcription factor is required for resistance to necrotrophic fungal pathogens. Plant J. 2006, 48, 592-605. [CrossRef] [PubMed]

22. Lai, Z.; Li, Y.; Wang, F.; Cheng, Y.; Fan, B.; Yu, J.Q.; Chen, Z. Arabidopsis sigma factor binding proteins are activators of the WRKY33 transcription factor in plant defense. Plant Cell 2011, 23, 3824-3841. [CrossRef] [PubMed]

23. Sheikh, A.H.; Eschen-Lippold, L.; Pecher, P.; Hoehenwarter, W.; Sinha, A.K.; Scheel, D.; Lee, J. Regulation of WRKY46 Transcription Factor Function by Mitogen-Activated Protein Kinases in Arabidopsis thaliana. Front. Plant Sci. 2016, 7, 61. [CrossRef] [PubMed]

24. Andreasson, E.; Jenkins, T.; Brodersen, P.; Thorgrimsen, S.; Petersen, N.H.; Zhu, S.; Qiu, J.-L.; Micheelsen, P.; Rocher, A.; Petersen, M.; et al. The MAP kinase substrate MKS1 is a regulator of plant defense responses. EMBO J. 2005, 24, 2579-2589. [CrossRef] [PubMed]

25. Qiu, J.-L.; Fiil, B.K.; Petersen, K.; Nielsen, H.B.; Botanga, C.J.; Thorgrimsen, S.; Palma, K.; Suarez-Rodriguez, M.C.; Sandbech-Clausen, S.; Lichota, J.; et al. Arabidopsis MAP kinase 4 regulates gene expression through transcription factor release in the nucleus. EMBO J. 2008, 27, 2214-2221. [CrossRef]

26. Ichimura, K.; Shinozaki, K.; Tena, G.; Sheen, J.; Henry, Y.; Champion, A.; Kreis, M.; Zhang, S.; Hirt, H.; Wilson, C.; et al. Mitogen-activated protein kinase cascades in plants a new nomenclature. Trends Plant Sci. 2002, 7, 301-308.

27. Teige, M.; Scheikl, E.; Eulgem, T.; Doczi, R.; Ichimura, K.; Shinozaki, K.; Dangl, J.L.; Hirt, H. The MKK2 pathway mediates cold and salt stress signaling in Arabidopsis. Mol. Cell 2004, 15, 141-152. [CrossRef]

28. Danquah, A.; de Zelicourt, A.; Colcombet, J.; Hirt, H. The role of ABA and MAPK signaling pathways in plant abiotic stress responses. Biotechnol. Adv. 2014, 32, 40-52. [CrossRef]

29. Balbi, V.; Devoto, A. Jasmonate signalling network in Arabidopsis thaliana: Crucial regulatory nodes and new physiological scenarios. New Phytol. 2008, 177, 301-318. [CrossRef] 
30. Farmer, E.E.; Alméras, E.; Krishnamurthy, V. Jasmonates and related oxylipins in plant responses to pathogenesis and herbivory. Curr. Opin. Plant Biol. 2003, 6, 372-378. [CrossRef]

31. Li, J.; Brader, G.; Palva, E.T. The WRKY70 transcription factor: A node of convergence for jasmonate-mediated and salicylate-mediated signals in plant defense. Plant Cell 2004, 16, 319-331. [CrossRef] [PubMed]

32. Agarwal, P.; Dabi, M.; Sapara, K.K.; Joshi, P.S.; Agarwal, P.K. Ectopic Expression of JcWRKY Transcription Factor Confers Salinity Tolerance via Salicylic Acid Signaling. Front Plant Sci. 2016, 7, 1541. [CrossRef] [PubMed]

33. Liu, C.; Zhang, X.; Zhang, K.; An, H.; Hu, K.; Wen, J.; Shen, J.; Ma, C.; Yi, B.; Tu, J.; et al. Comparative Analysis of the Brassica napus Root and Leaf Transcript Profiling in Response to Drought Stress. Int. J. Mol. Sci. 2015, 16, 18752-18777. [CrossRef]

34. Takahashi, F.; Yoshida, R.; Ichimura, K.; Mizoguchi, T.; Seo, S.; Yonezawa, M.; Maruyama, K.; Yamaguchi-Shinozaki, K.; Shinozaki, K. The mitogen-activated protein kinase cascade MKK3-MPK6 is an important part of the jasmonate signal transduction pathway in Arabidopsis. Plant Cell 2007, 19, 805-818. [CrossRef] [PubMed]

35. Gunapati, S.; Naresh, R.; Ranjan, S.; Nigam, D.; Hans, A.; Verma, P.C.; Gadre, R.; Pathre, U.V.; Sane, A.P.; Sane, V.A. Expression of GhNAC2 from G. herbaceum, improves root growth and imparts tolerance to drought in transgenic cotton and Arabidopsis. Sci. Rep. 2016, 6, 24978. [CrossRef]

36. Hossain, M.A.; Ye, W.; Munemasa, S.; Nakamura, Y.; Mori, I.C.; Murata, Y. Cyclic adenosine $5^{\prime}$-diphosphoribose (cADPR) cyclic guanosine $3^{\prime}, 5^{\prime}$-monophosphate positively function in $\mathrm{Ca}^{2+}$ elevation in methyl jasmonate-induced stomatal closure, cADPR is required for methyl jasmonate-induced ROS accumulation NO production in guard cells. Plant Biol. 2014, 16, 1140-1144.

37. Hopper, D.W.; Ghan, R.; Schlauch, K.A.; Cramer, G.R. Transcriptomic network analyses of leaf dehydration responses identify highly connected $\mathrm{ABA}$ and ethylene signaling hubs in three grapevine species differing in drought tolerance. BMC Plant Biol. 2016, 16, 118. [CrossRef]

38. Caarls, L.; Pieterse, C.M.; Van Wees, S.C. How salicylic acid takes transcriptional control over jasmonic acid signaling. Front Plant Sci. 2015, 6, 170. [CrossRef]

39. Li, S.; Fu, Q.; Chen, L.; Huang, W.; Yu, D. Arabidopsis thaliana WRKY25, WRKY26, and WRKY33 coordinate induction of plant thermotolerance. Planta 2011, 233, 1237-1252. [CrossRef]

40. Qin, Y.; Tian, Y.; Liu, X. A wheat salinity-induced WRKY transcription factor TaWRKY93 confers multiple abiotic stress tolerance in Arabidopsis thaliana. Biochem. Biophys. Res. Commun. 2015, 464, 428-433. [CrossRef]

41. Tamura, K.; Peterson, D.; Peterson, N.; Stecher, G.; Nei, M.; Kumar, S. MEGA5: Molecular evolutionary genetics analysis using maximum likelihood, evolutionary distance, and maximum parsimony methods. Mol. Biol. Evol. 2011, 28, 2731-2739. [CrossRef] [PubMed]

42. Fei, X.; Shi, Q.; Yang, T.; Fei, Z.; Wei, A. Expression Stabilities of Ten Candidate Reference Genes for RT-qPCR in Zanthoxylum bungeanum Maxim. Molecules 2018, 23, 802. [CrossRef] [PubMed] 